\title{
THE MODEL OF CONTAINER FEEDER LINE ORGANIZATION FOCUSED ON THE NATURE AND PARAMETERS OF EXTERNAL CONTAINER FLOWS
}

\author{
Oleksii Drozhzhyn*, Yuliia Koskina \\ Odesa National Maritime University, Odesa, Ukraine \\ *E-mail of corresponding author: alexey.drozhzhyn@ukr.net
}

\section{Resume}

This article considers the trunk lines, connected with the feeder region as the external environment for the system - feeder lines (its subsystems are container flows, ports and container ships). Hub ports are considered to be the boundary of the system and the external environment. Thus, mathematical models were simulated for the two levels. At the first level, container flows are determined (based on statistical data), which enter and exit the hub. At the second level, the mathematical model allows to find for the feeder line: volumes of container flows, the total capacity of the ships which serves the cargo, and parts of the distribution of this capacity between feeder ports.

\section{Article info}

Received 16 July 2020

Accepted 24 August 2020

Online 2 February 2021

\section{Keywords:}

feeder line,

container transportation, liner shipping, transport technologies, transport systems

\section{Introduction}

There are many scientific papers regarding hub and spoke systems in maritime container shipping. The topic of the presented paper covers three large sections simultaneously: geography of transport systems [1], organization of ship's operation [2] and container network technologies optimization [3].

The new generation research-studies, dedicated to container shipping, often use the models, proposed by highly cited authors [4-5].

Trunk and feeder network design problems were suggested to be solved by methods like: variable neighborhood search [6], genetic algorithm-based heuristic [7], liner programming, particularly, using simplex algorithm [8], mixed integer liner programming [9-10].

\section{The model of relationship between the feeder system parameters for the container traffic and external environment}

Feeder container lines are not a separate system; they are in close interaction with the environment - a system of trunk container lines. Their interaction is an integral part of the world container shipping system - the trunk-feeder communication and their interrelation occurs at the level of vessels, ports and container flows. Making the decisions about organizing a feeder line, the ship-owner (or operator) must determine the region and, accordingly, the basic ports of call of the created line, which cannot be done without the information about how the trunk container lines in the region are working. That is, container flows that arise or fade in the routes of trunk container lines and their distribution between ports are the main input information for substantiating the structure of the feeder line.

The above-mentioned system and the external environment are hierarchical: the system of feeder lines is "subordinated" to the system of trunk container lines. Thus, these systems function (probably must function) as agreed ones to ensure delivery of cargoes in containers during the trunk-feeder service in acceptable time for cargo owners, that is impossible without the coordination of the basic parameters of these systems. To such parameters, in this case, are referred the fleet container capacity, the volume of container flows between ports and the transport links "hub port - feeder port". The latter, in turn, form areas of feeder lines.

Figure 1 presents the model of interrelation of ports, vessels and container flows which are the parts of the systems of trunk and feeder lines. The following is a brief description.

First of all, it is necessary to determine the relationship between these systems at the port level. In the system of trunk container lines, hubs are to be allocated, between which the goods in containers are carried as a part of the 


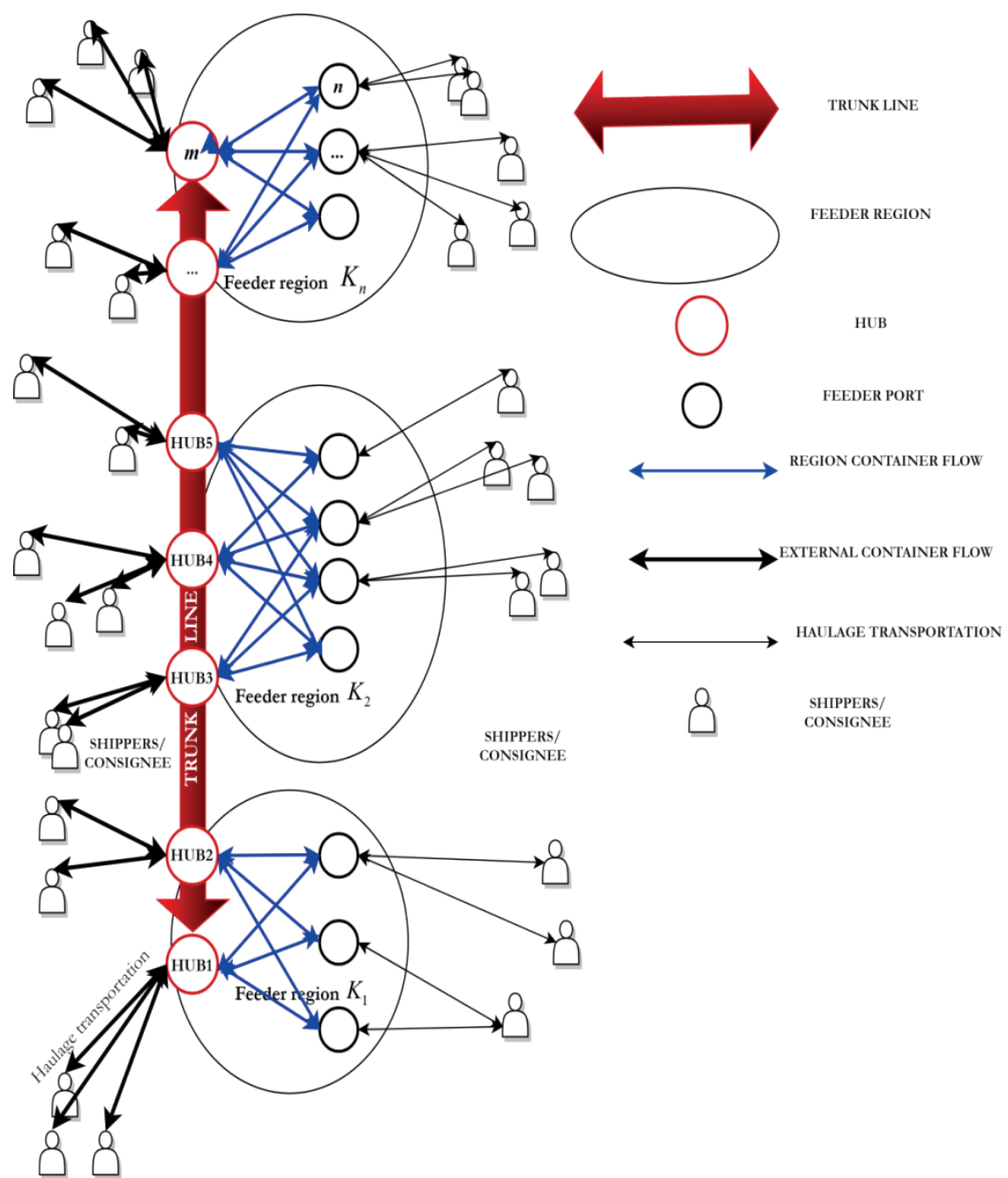

Figure 1 The model of the interrelation of ports, vessels and container flows

global commodity flows of world trade. This means that the volumes of container flows in the system of trunk lines are formed according to the structure and volume of the world trade.

There are $m$ hubs and $i=\overline{1, m}$ are the indexes of these ports. All the hub ports can be geographically divided into groups. As such, a region is established within which rational consideration of feeder directions is considered. That is, $n$ feeder regions are separated. The aggregate of the feeder regions forms the geographical characteristics of the feeder line system. In fact, the feeder regions are superimposed on the main trunk routes, providing full coverage of all the hub ports and feeder ports. Thus, one more index $j=\overline{1, n}$ is introduced for the hub ports, which determines that the hub port belongs to the feeder region. That is, hubs are considered as the points of intersection of the feeder system and the external environment (trunk lines), which is formally taken into account in the double indexation of ports - from the point of view of trunk lines ( $i=\overline{1, m}$ ) and from the point of view of belonging to the feeder regions $(j=\overline{1, n})$. In each feeder region feeder ports $K_{j}$ are selected, $j=\overline{1, n}$ and $k_{j}=\overline{1, K_{j}}, j=\overline{1, n}$ - the index of feeder ports of the feeder region $j$.

In the system of feeder container lines, hubs are connected with the feeder ports by corresponding services. Note that the given feeder ports are considered as potential ports to be included in feeder services and, consequently, the set of considered feeder ports may not be fully involved in the feeder service at a given time. Thus, depending on volumes of the container traffic in the feeder region and their distribution among the ports of the region in this time period, this or that port may be included or excluded from the feeder services. For each hub port, the volume of incoming (or outbound) container flow $Q_{i j}^{\text {exp }}, Q_{i j}^{i m p}$ respectively can be determined. It is obvious that the information completeness and reliability (quantitative and qualitative parameters), regarding the container flows, play a key role for this problem solving.

For consideration, only general cargoes typical for containerization should be accepted. Although the bulk cargoes are also involved in the practice, contested proposed problem, they cannot be included in the analysis. Most often, the container transportation of such bulk cargoes is profitable for the carrier only when it is necessary to utilize the free space (on unbalanced routes). Such cases revenue is additional.

The container flows information sources are provided by analytical companies that offer marketing research at 


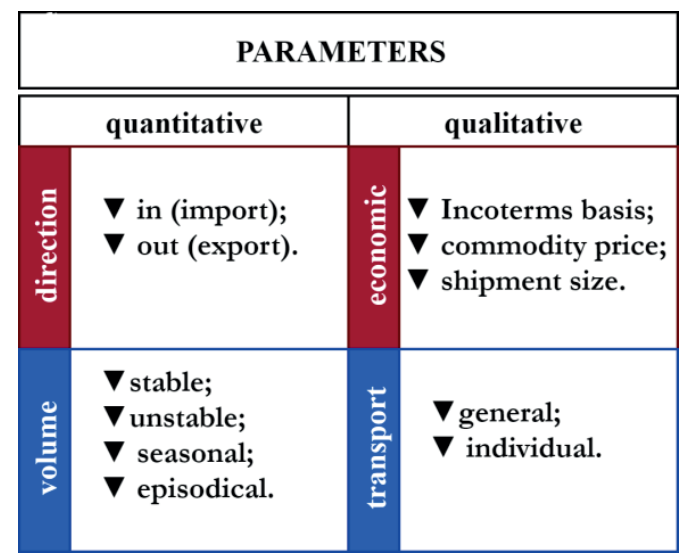

Figure 2 Data groups for container flows evaluation

the request of the carrier (Figure 2).

These values are formed as a result of integration of incoming (or output) container flow from/to other hub ports. A data set of container flows links the system of hubs within the trunk lines.

Geographically, in each feeder region $j=\overline{1, n}$ there are hub ports (one and more) and a set of feeder ports.

The feeder ports are an intermediate (in most cases) link in the intermodal container delivery system (it means that some cargo in containers is delivered to the region where the feeder port is located), as the rest of the cargo goes to the regions of the country (or several countries). At the same time, the situation may arise that the same dispatch (destinations) points may be attracted to different feeder ports, that may result in use of several feeder ports simultaneously.

Therefore, when creating a feeder container line and solving the issue of inclusion of this or that feeder (potential) port in the line should be taken into account the geography of regions of the cargo flow origin. Thus, for each feeder port of a given region, quantities $Q_{i k}^{i n}, Q_{i k j}^{o u t}$ can be determined that characterize the potential volumes of input and output containers for the feeder ports in a certain direction, taking into account the geography of foreign trade links.

Considering the above-mentioned substantiation that the same container ports can be attracted to various feeder ports, the following is true:

$\sum_{k j=1}^{K_{j}} Q_{i k j}^{i n} \geq Q_{i j}^{i m p},\left(i=\overline{1, n}, i \in G_{j}\right)$,

$\sum_{k_{j=1}}^{K_{j}} Q_{i k_{j}}^{o u t} \geq Q_{i j}^{\exp },\left(i=\overline{1, n}, i \in G_{j}\right)$,

where $G_{j}$ is a set of the hub ports in the region.

In accordance with these inequalities, the volume of input/output container flows in/from feeder ports may exceed the volume of input/output container ports of hubs precisely because the values $Q_{i k j}^{i n}, Q_{i k j}^{o u t}$ are potential, while $Q_{i j}^{\exp }, Q_{i j}^{i m p}$ are already established. Note that the feeder service is more flexible than trunk, therefore, from the point of view of the tasks solved in this study, $Q_{i k j}^{i n}, Q_{i k j}^{o u t}$ are considered as the potential ones.

Some regional container traffics are served by feeder vessels of companies operating in a particular region. Based on the analysis of existing feeder services in each region, it is possible to establish the average volume of containers that are already served (meaning that the transportation of this number of containers is provided by already functioning feeder services). These volumes can be estimated as:

$\sum_{i \in G_{j}} \sum_{l_{j}=1}^{L_{j}} D_{i k_{j}}^{l j} \cdot s_{i k_{j}}^{l j} \cdot p_{i k j}^{l j},\left(k_{j}=\overline{1, K_{j}}, j=\overline{1, n}\right)$,

where $l_{j}$ - current feeder service in region $j ; L_{j}$ - number of feeder services in region $j ; D_{i k j}^{l j}$ - container capacity of the vessels of $l_{j}$ feeder service in region $j$ that connects the feeder port with hub port $i$; $p_{i k_{j}}^{l_{j}}$ - coefficient of variation, which allows moving from the container capacity of the vessel to the carrying capacity (in TEU); $0<s_{i k_{j}}^{l_{j}} \leq 1$ coefficient that corrects the carrying capacity of vessels considering their actual loading capacity. Here, the following should be noted. Depending on the port and the time period considered, the vessels operating between the feeder ports can use container capacity fully or just partly. The coefficient $s_{i k_{j}}^{l_{j}}$ allows to consider this fact when assessing the potentially possible volume of carrying work on the new feeder line. It can also be used in estimating the competitiveness of the existing feeder service, namely: if this service is characterized by the low competitiveness (for instance, due to inappropriate pricing policy, timetable, etc.), then the new service has a chance to "take away" part of cargo flows. Thus, the coefficient $s_{i k_{j}}^{l_{j}}$ performs two functions, it takes into account the real terms of the operation of feeder vessels both at the level of their operating and at the level of competition.

Considering the "covered" container flows on the ports, it is possible to determine the value of $Q_{i k_{j}}^{f p}$, which defines the potential volume of carriage for each feeder port in the region:

$$
\begin{aligned}
& Q_{i k_{j}}^{f f}=\left(Q_{i k_{j}}^{i n}+Q_{i k_{j}}^{\text {out }}\right)-\sum_{i \in G_{j}} \sum_{l j=1}^{L_{j}} D_{i k_{j}}^{l j} \cdot s_{i k_{j}}^{l j} \cdot p_{i k_{j},}^{l j}, \\
& \left(k_{j}=\overline{1, K_{j}}, j=\overline{1, n}\right),
\end{aligned}
$$

Thus, the interrelation of the environment containing a set of trunk lines and the feeder system of container lines at the port and container traffic levels is considered. 
The next step is to establish a relationship between the data system and the environment at the vessel level. It should be noted here that the vessel itself is not an element of the system and the environment and their relationship is manifested indirectly through the container traffic. In essence, the feeder and trunk vessels provide the interrelation of the system and the environment through the container flows, realizing the physical distribution and their mating.

The segmentation of vessels to the trunk and feeder is inherent in commercial practice, that is, there are no architectural and constructive types of "feeder" or "trunk" vessels, as while the basis of segmentation is a container capacity, which also determines the vessel draft, and hence the physical possibility of the vessel call at one or another feeder port.

In the world container fleet sets of the trunk and feeder vessels are distinguished. The trunk vessels belong to the system of trunk lines; feeder ones, respectively, belong to the system of feeder lines. The container capacity is used to characterize the fleet of both systems.

The world container fleet capacity serving the trunk lines $D^{t}$, TEU (Twenty-foot Equivalent Unit) is determined on the forecasts of volumes of vessel demolition $D^{d}$ and ordering the new vessels $D^{b}$ :

$$
D^{t}=D^{t^{\prime}}+D^{b}+D^{d}
$$

where $D^{t^{\prime}}$ - container capacity (TEU) of the trunk vessels at the current moment. This container capacity $D^{t}$ is distributed between trunk lines that cover port hubs.

In the system of trunk-feeder lines, it is necessary to allocate subsystems connected with specific regions. These subsystems include relevant elements of the trunklevel system (port-hub of the region) and feeder ports of the region. Each region is separate, which is determined by the specificity of cargo flows caused by the world trade. Interrelation of regions is determined solely in the form of a single connecting link - the main and feeder fleet, which is distributed by region, considering the demand.

Container capacity of the fleet serving feeder lines is $D$ (TEU). This value is also established based on forecasting the amount of demolition of tonnage $D^{f d}$ (TEU) and supplies of new vessels $D^{f b}$ (TEU). So:

$$
D^{f}=D^{f^{\prime}}+D^{f b}+D^{f d}
$$

where $D^{f^{\prime}}$ - container capacity (TEU) of feeder vessels at the current time.

The feeder fleet is distributed among feeder regions. So, the following is true:

$$
D^{f}=\sum_{j=1}^{n} \sum_{i \in G_{j}} \sum_{k_{j}=1}^{K_{i}} \sum_{l_{j=1}}^{L_{j}} D_{i k_{j}}^{l_{j}} .
$$

Thus, at the conceptual and formalized levels, interrelations between the two hierarchical levels, which are parts of the world system of container lines, are established. As a result, the container capacity of the fleet, the volume of container flows and their distribution between ports are formalized.

\section{Substantiation of ports, vessels and the prospective volume of carriage for feeder lines considering the interrelations with the external environment}

The presented above model harmonizes container flows and ports on the two levels of the international sea container carriage system - trunk and feeder.

Based on information on perspective container cargo flows and changes in the structure of the fleet at both levels, the ship-owner willing to organize the feeder service should substantiate promising feeder ports and volumes of transportation, as well as determine whether there is enough fleet available to ensure the functioning of both existing and new lines and to solve the task of distributing this fleet considering commercial interests. The presented above conceptual model can just help in solving these tasks.

The next stage is modeling on that base the next one model which will consider the specificity of the hierarchy, as well as its other properties of the levels, in accordance with parameters that were defined above. So, this can be stipulated as follows: for a given shipping company, it is necessary to find the optimal transport links "feeder port/ hub port" (for organization of the feeder lines in the future) and distribute the fleet available to the company in such a way that the efficiency of feeder services to be maximal. As the efficiency of feeder services, one means here the annual profit from the operation of the container vessels on the feeder lines, which would satisfy the specified profitability. Thus, it is necessary to maximize profit, provided it is limited to a given value of profitability. This approach fully corresponds to the practice of modern shipping business.

Since the searching interrelation is hierarchically two-level, its description is mathematically expressed in the form of models of two levels: trunk and feeder. Theoretically, the trunk model covers all the trunk lines and corresponding ports. The feeder-level model covers all the regions and feeder ports (already involved in feeder services and potential). However, in practice, companies that organize feeder lines do not even potentially consider their presence in all the regional markets, so it is advisable to specify the limits for the task and the corresponding models, that is, the establishment of the set of regions that are considered by the company as potential ones.

Assume that $j=\overline{1, n^{\prime}}$ - this is an ordered subset of the set of all the regions allocated in the system of the sea container transport. As it was mentioned previously the regions can be identified as a subsystem of the hierarchical unity of the "trunk-feeder lines".

Therefore, there is one trunk-level model that covers hubs of selected regions $j=\overline{1, n^{\prime}}$ and $n^{\prime}$ feeder-level models, corresponding to the regional subsystems of the 
feeder system. Each model is optimization, since the desire to maximize the efficiency of transport services is natural for the modern transport services market at any level of its searching.

Special situations that arise for some participants in the market of transport services (or their associations), in relatively small periods of time due to competition, when the efficiency provides secondary to other objectives of competition, in the context of the searched problem may be omitted without violating the specificity in accordance with a situation that is modeled.

Mathematically, this structure is a set of $n^{\prime}+1$ interconnected optimization models, which in terms of further solution is well understood in modern scientific literature.

The trunk-level model should provide an optimal distribution of the container traffic between regions and hubs, considering the information on the output of hub ports. As a criterion of optimality, it is proposed to use the generalized profit of ship-owners and companies operating in the system of trunk lines. At the core of the profit origin is the averaged information on costs and revenues of carriers. This model has to provide, as outgoing information, the "landmark" for the distribution of container traffic between regions and hub ports, considering interests of ship-owners and attraction of container traffic to hubs and regions in general. In turn, the information received on volumes of traffic (container traffic) at the trunk level is the input (exogenous) information for the feeder system (as previously noted, the linkage of the models of the trunk and feeder levels are container flows). Therefore, in the model of the trunk level of the container traffics are variables and their optimal values will provide efficiency for the fleet of companies (in general), considering the above limiting conditions.

Assume that the container capacity of the fleet, serving the trunk lines $D^{w}$, is enough to make a service of trunk lines, so it is not to be used in optimizing.

The data for modeling are the following:

$P_{j}(j=\overline{1, n})$ - total capacity of container terminals in region $j ; K_{j k}(j, k=\overline{1, n})$ - potential cargo flows (volumes and structure) of the region for the transportation of containerized cargo from region $j$ to region $k$ for container flows considering the possibility of their attraction to different ports and regions (this means the inland part of transportation). Volumes $K_{j k}$ are established based on the maritime world trade geography analysis;

$f_{j k}(j, k=\overline{1, n})$ - averaged profit rate (for TEU) for transportation between regions $j, k$;

$r_{j k}(j, k=\overline{1, n})$ - averaged cost standard (for TEU) for transportation between regions $j, k$.

The parameters are $Y_{j k} \geq 0$ the volumes of transportations between regions $j, k=\overline{1, n}, j \neq k$.

The objective function reflects the generalized revenue from the operating of vessels in traffic between regions:

$\sum_{j=1}^{n \Sigma} \sum_{\substack{k=1 \\ k \neq j}}^{n \Sigma} Y_{j k} \cdot\left(f_{j k}-r_{j k}\right) \rightarrow \max$
In this case, the constraints on the capacity of container terminals of regions should be ensured:

$$
\sum_{\substack{k=1 \\ k \neq j}}^{n} Y_{j k} \sum_{\substack{k=1 \\ k \neq j}}^{n} Y_{k j} \leq P_{j},(j=\overline{1, n}),
$$

where $\sum_{\substack{k=1 \\ k \neq j}}^{n} Y_{j k}$ - volumes of container flows from region $j$; $\sum_{k=1}^{n} Y_{k j}$ - volumes of container flows to region $j$. $k \neq j$

In addition, the constraint on potential cargo flows must be fulfilled:

$Y_{j k} \leq K_{j k},(j, k=\overline{1, n})$.

The optimal values of $Y_{j k}^{*}$ allow to estimate $Q_{i j}^{\exp }, Q_{i j}^{i m p}$, ( $i=\overline{1, m}, j=\overline{1, n}$ ) - the distribution of container flows between hub ports as follows:

$Q_{i j}^{\exp }=v_{i j} \cdot \sum_{\substack{k=1 \\ k \neq 1}}^{n} Y_{i k}^{*},(j=\overline{1, n}, i \in G)$,
$Q_{i j}^{i m p}=v_{i j} \cdot \sum_{\substack{k=1 \\ k \neq 1}}^{n} Y_{k j}^{*},(j=\overline{1, n}, i \in G)$,

where $v_{i j}$ - the coefficients of the distribution of container flows that occurs in the region on the hub port providing the inequality: $\sum_{i \in G j} v_{i j}=1,(j=\overline{1, n})$. Wherein the values of vij can be set based on the existing statistics of distribution of container flows in ports of the region.

Transport links "feeder port/hub port" are displayed as a container traffic that connects these two categories of ports.

Feeder services that are considered $L_{j}$ in region $j$, $l_{j}=1$ is existing or hypothetical (that is, considered as a potential) service of the company for which the network of the feeder lines is substantiated. Thus, other $L_{j}-1$ services in each region $j$ are in varying degrees competing. The degree of competition depends, first of all, on the intersection of ports of the feeder services and is further determined by the tariff policy of companies and other factors.

If $X_{i k j}^{i n}, X_{i k_{j}}^{\text {out }},\left(j=\overline{1, n}, i \in G_{j}, k_{j}=\overline{1, K}\right)$ are volumes of container flows to/from the port $k_{j}$ from/to the hub port $i$ of region $j$, they are potential cargoes for the network of the feeder lines to be organized. These values are variables in feeder-level models and are determined in the process of optimization. These potential cargo flows can match the capabilities of this company's fleet, and may not meet (for example, the shipping capacity of the company's fleet may not be enough to provide the entire volume of containers that will be claimed for transportation in the future).

According to the indicated above that $l_{j}=1,(j=\overline{1, n})$ corresponds to the strategy of the company on the organization of the feeder lines network, the fleet of feeder vessels of this company is characterized by $D^{*}=\sum_{j=1}^{n^{\prime}} \sum_{k_{j}=1}^{K_{j}} D_{i k_{j}}^{l_{j}},\left(l_{j}=1\right)$ as the container capacity and $D^{*}$ includes all the feeder vessels of a company operating on all the services. Naturally, the individual components of this value are $D_{i k j}^{l_{j}}=0,\left(l_{j}=1\right)$ for some $i, j, k_{j}$ 
Since the task in question is regarding the distribution of the fleet of the company between the planned possible feeder lines, the control parameters $z_{i k j} \geq 0$, $\left(j=\overline{1, n}, i \in G_{j}, k_{j}=\overline{1, K_{j}}\right)$ are introduced being the container capacity of the vessels for servicing in region $j$ of the feeder line destinated to hub port $i$ and feeder port $k_{j}$.

For these control parameters the following is true:

$\sum_{j=1}^{n^{\prime}} \sum_{i \in G j} \sum_{k j=1}^{K j} Z_{i k j}=D^{*}$

It should be noted that the optimal variant of distribution of the total container capacity of the company's fleet will correspond to values of individual $Z_{i k_{j}}$ ones that are inappropriate in terms of logic: for instance, $Z_{i k_{j}}=34$ or $Z_{i k j}=5$ or the others alike, for individual $i, j, k_{j}$, since there are no ships of this container type physically, therefore these values are not valid in the given terms and for the given task. Therefore, the following ways to correct the situation are proposed: firstly, it is necessary to specify $A$ - the lower limit of $Z_{i k_{j}}$ considering the actual container capacity of company's vessels. Secondly, the result of optimization on the model is a basis for the decision-making and subject to manual adjustment in the light of common sense.

Thus, the constraint on container capacity of vessels is following:

$$
Z_{i k_{j}} \geq A,\left(j=\overline{1, n}, i \in G_{j}, k_{j}=\overline{1, K_{j}}\right) .
$$

Besides, it is necessary to take into account the port limits of allowable draft of vessels, so there should be constraints on the container capacity of vessels $A_{i k j}$ regarding ports of call:

$Z_{i k j} \geq A_{i k j},\left(j=\overline{1, n}, i \in G_{j}, k_{j}=\overline{1, K_{j}}\right)$.

Distribution of the fleet should correspond to cargo flows. Therefore, it is necessary to introduce the term of conformity of the vessels' capacity to volumes of potential container flows. To do this, the process of forming the cargo flows is analyzed and formalized.

Data on volumes of transportation (container flows) in the trunk container system $Q_{i k j}^{i n}, Q_{i k_{j}}^{o u t}$, ( $j=\overline{1, n}, i \in G_{j}, k_{j}=\overline{1, K_{j}}$ ) is the input (exogenous) information for the feeder system. In particular, based on this information, based on belonging of hub ports for a specific region, aggregate information is generated on volume of the container flows in the region:

$$
\begin{aligned}
& \sum_{i=G_{j}} Q_{i j}^{i m p},(j=\overline{1, n}), \\
& \sum_{i=G_{j}}^{\Sigma} Q_{i j}^{\exp },(j=\overline{1, n}),
\end{aligned}
$$

where $G_{j}$ is a set of hub ports in the region.

Not all the container trunk lines are assimilated by the feeder ports, since some cargoes in containers follow the inland transport, that is, in the maritime transportation for such cargoes, the port-hub is the final (or initial) destination (departure).

Each hub port has coefficients $0 \leq \lambda_{i j}^{i m p} \leq 1$ and $0 \leq \lambda_{i j}^{\exp } \leq 1$ that represent the proportion of containerized cargo delivered by the trunk-and-feeder system:

$\lambda_{i j}^{i m p}=\frac{Q_{i j}^{i m p}-Q_{i j}^{i m p, f i n}}{Q_{i j}^{i m p}}$,

$\lambda_{i j}^{\exp }=\frac{Q_{i j}^{\exp }-Q_{i j}^{\exp , s t}}{Q_{i j}^{\exp }}$,

where $Q_{i j}^{i m p, f i n}$ - volumes of the input container flows to hub port $i$ of region $j$ for which this hub port is the final point of destination;

$Q_{i j}^{\exp , s t}$ - volumes of the output container flows from hub port $i$ of region $j$ for which this hub port is the starting point of sea carriage.

Thus, for the feeder ports (which are involved in feeder services or those potentially considered for new services) from the trunk container traffic the following volume is allocated:

$\lambda_{i j}^{i m p} \sum_{i \in G_{j}} Q_{i j}^{i m p},(j=\overline{1, n})$,
$\lambda_{i j}^{\exp } \sum_{i \in G_{j}} Q_{i j}^{\exp },(j=\overline{1, n})$.

Obviously, all the container lines of existing feeder lines (with their specified particulars) and those lines that are organized (new ones) should be appropriate to the input/output container hub ports in the region:

$\lambda_{i j}^{i m p} \cdot Q_{i j}^{i m p}=\sum_{k_{j}=1}^{K_{j}} X_{i k_{j}}^{\text {out }}+\sum_{k_{j}=1}^{K_{j}} \sum_{l_{j}=2}^{L_{j}} v_{i k_{j}}^{\text {out }}$.
$D_{i k_{j}}^{l_{j}} \cdot s_{i k_{j}}^{l_{j}} \cdot p_{i k_{j}}^{l_{j}},\left(j=\overline{1, n}, i \in G_{j}\right)$,

$\lambda_{i j}^{\exp } \cdot Q_{i j}^{\exp }=\sum_{k_{j}=1}^{K_{j}} X_{i k_{j}}^{i n}+\sum_{k_{j}=1}^{K_{j}} \sum_{l_{j}=2}^{L_{j}} v_{i k_{j}}^{i n}$.

$\cdot D_{i k_{j}}^{l_{j}} \cdot s_{i k_{j}}^{l_{j}} \cdot p_{i k_{j}}^{l_{j}},\left(j=\overline{1, n}, i \in G_{j}\right)$,

where $v_{i k j}^{\text {in }}, v_{i k j}^{\text {out }}$ - coefficients that take into account the imbalance of export/import between the feeder ports and port hubs of the given region. The introduction of these coefficients allows the fleet's carrying capacity not to be evenly distributed (50\%:50\%) between the two directions of transportation (in hub ports, from the hub ports), but to consider the uneven use of the fleet, as well. The following formulas can be used to calculate the coefficients:

$$
\begin{aligned}
& v_{i k_{j}}^{o u t}=\frac{Q_{i k_{j}}^{o u t}}{Q_{i k_{j}}^{i n}+Q_{i k_{j}}^{\text {out }}},\left(j=\overline{1, n i} \in G_{j}, k_{j}=\overline{1, K_{j}}\right), \\
& v_{i k_{j}}^{\text {in }}=\frac{Q_{i k_{j}}^{i n}}{Q_{i k_{j}}^{i n}+Q_{i k_{j}}^{o u t}},\left(j=\overline{1, n i} \in G_{j}, k_{j}=\overline{1, K_{j}}\right) .
\end{aligned}
$$

In Equations (22-23) $Q_{i k j}^{i n}, Q_{i k_{j}}^{o u t}$ are estimate potential volumes of input/output containers for feeder ports $k_{j}$ in the direction to/from hub port $i$.

Thus, Equations (24-25) reflect the balance of the container flows in the feeder system and the environment on each hub port of each region in each direction (import 
/ export). In the left parts of the equations are container flows of trunk lines, considering the share of feeder ports.

At the same time, in the right part of these constraints, the feeder services $l_{j}=\overline{2, L_{j}},(j=\overline{1, n})$ are considered, that is, in the regional services of all the companies other than those for which research is conducted. In this case, even the existing services of the company are excluded from consideration, and the distribution of the fleet is carried out again, not but as a change of existing. This is expedient, since by adding or correcting a structure that has ceased to be optimal under the new terms, it is quite difficult to achieve an optimum approximation. While approaching the distribution of ships in the new environment, without considering the existing service structure, it is possible to get better distribution in terms of efficiency.

If companies are required to maintain any kind of feeder services in their current form, for certain circumstances (for example, a competitive strategy for a particular region), then this can be taken into account by exception of such $D_{i k_{j}}^{l_{j}}\left(l_{j}=1\right)$ determining $D^{*}$ Another way that can be used is to put $Z_{i k_{j}}^{*}$ as constants when forming $\sum_{j=1}^{n^{\prime}} \sum_{i \in G_{j}} \sum_{k_{j}=1}^{K_{j}} Z_{i k_{j}}=D^{*}$.

Note that unlike the feeder ports, the container traffic redistribution between hub ports is much less frequent, as the inertia increases, depending on the size of the object, in this case, such an object is the container hub port. However, such a task as the redistribution of container traffic is the subject of special research and is not considered in this paper.

Next, it is necessary to "link" the distribution of vessels with container traffic.

Previously, it was determined that considering the "covered" container traffic by ports, it is possible to determine the prospects (traffic volumes) for each feeder port in the region.

Considering the withdrawal of services of the carrier company, one can obtain:

$$
\begin{aligned}
& Q_{i k_{j}}^{f p}=\left(Q_{i k_{j}}^{i n}+Q_{i k_{j}}^{o u t}\right)-\sum_{i \in G i} \sum_{l_{j}=2}^{L_{j}} D_{i k_{j}}^{l_{j}} . \\
& \cdot s_{i k_{j}}^{l_{j}} \cdot p_{i k_{j}}^{l_{j}},\left(k_{j}=\overline{1, K_{j}}, j=\overline{1, n}\right),
\end{aligned}
$$

and then the following reflects the potential demand for transport services:

$$
X_{i k_{j}}^{i n}+X_{i k_{j}}^{\text {out }} \leq Q_{i k_{j}}^{f p},\left(j=\overline{1, n}, i \in G_{j}, k_{j}=\overline{1, K_{j}}\right) .
$$

The condition of "linking" the fleet of the company and the total potential demand:

$$
\begin{aligned}
& \sum_{j=1}^{n^{\prime}} \sum_{i \in G_{i}} \sum_{k_{j}=1}^{K_{j}}\left(X_{i k_{j}}^{i n}+X_{i k_{j}}^{\text {out }}\right)-\sum_{j=1}^{n^{\prime}} \sum_{i \in G_{i}} \sum_{k_{j}=1}^{K_{j}}\left(Z_{i k_{j}}+Z_{i k_{j}}^{\text {add }}\right) . \\
& \cdot s_{i k_{j}} \cdot p_{i k_{j}}=0,
\end{aligned}
$$

where $\sum_{j=1}^{n^{\prime}} \sum_{i \in G_{i}} \sum_{k j=1}^{K_{j}}\left(X_{i k_{j}}^{i n}+X_{i k_{j}}^{\text {out }}\right)$ is the total potential carriage for the company in the region (in both directions of transportation - from hub and to hub);

$\sum_{j=1}^{n^{\prime}} \sum_{i \in G_{i}} \sum_{k_{j}=1}^{K_{j}} Z_{i k_{j}} \cdot s_{i k_{j}} \cdot p_{i k_{j}}$ is the annual capacity (in TEU) of vessels of a company which is adjusted considering the actual loading of the vessel $0<s_{i k_{j}}^{l_{j}} \leq 1$ in capacity; $\sum_{j=1}^{n^{\prime}} \sum_{i \in G_{i}} \sum_{k_{j}=1}^{K_{j}} Z_{i k_{j}}^{a d d} \cdot s_{i k_{j}} \cdot p_{i k_{j}} \quad-\quad$ annual carrying capacity of vessels, which is needed to be additionally involved in serving feeder services in the region;

$Z_{i k j}^{a d d}$ - is a control parameter that displays the required additional container capacity of the vessels operating in the region in the direction of the hub port-feeder port. The necessity of this parameter is explained by the fact that the container capacity of the fleet of the company may not correspond to the prospective volume of traffic. For the correctness of the further solution and compliance with requirement of inevitability of the variables, and, in particular, $Z_{i k_{j}}^{\text {add }} \geq 0$ there is requirement:

$\sum_{j=1}^{n^{\prime}} \sum_{i \in G_{i}} \sum_{k_{j}=1}^{K_{j}}\left(X_{i k_{j}}^{i n}+X_{i k_{j}}^{\text {out }}\right) \geq$

$\geq \sum_{j=1}^{n^{\prime}} \sum_{i \in G_{i}} \sum_{k_{j}=1}^{K j} Z_{i k_{j}} \cdot s_{i k_{j}} \cdot p_{i k_{j}}$.

After a detailed description of the control parameters and constraints of the model, it is necessary to formulate an objective function, that is an optimization criterion that corresponds to the natural condition - the ship owner's request for maximizing efficiency. It was determined above that, under the effectiveness of feeder services the annual profit from the operating of container vessels on the feeder network is understood, which would satisfy the specified necessary level of profitability.

Efficiency of the vessels is formed from two components, such as costs (variable and fixed) and revenues from carriages of goods in containers. For this level, the freight rate per $1 \mathrm{TEU}$ and the costs per unit container capacity can only be determined in aggregated way (for example, without considering the structure of container traffic, etc.).

Variable $r_{i k_{j}}$ means the averaged level of operating costs for use of the container vessels (in this case, use of the container capacity of the vessels) in the direction hub port $i$ - feeder port $k$ (and it is assumed that this level includes both variable and fixed costs of vessels, considering the specificity of the feeder vessels and searched ports) and if $f_{i k j}$ is the average profit rate from use of the container vessels (using container capacity of vessels) in the direction hub port $i$-feeder port $k$, then the profit from operating of the company's vessels on the feeder lines will be:

$$
\begin{aligned}
& \sum_{j=1}^{n^{\prime}} \sum_{i \in G_{j}} \sum_{k_{j}=1}^{K_{j}}\left(f_{i k_{j}}-r_{i k_{j}}\right)\left(Z_{i k_{j}}+Z_{i k_{j}}^{a d d}\right) s_{i k_{j}} \cdot p_{i k_{j}}- \\
& -r^{\text {add }} \sum_{j=1}^{n^{\prime}} \sum_{i \in G_{j}} \sum_{k_{j}=1}^{K_{j}} Z_{i k_{j}}^{a d d} \rightarrow \max ,
\end{aligned}
$$

where $r^{\text {add }} \cdot Z_{i k j}^{\text {add }}$ is the cost of engaging the additional tonnage by time chartering (for example, available tonnage in the market from other regions), respectively, $r^{\text {add }}$ is the average time charter rate per a container unit. 
It was noted above that the profit should not be simply maximized, but should correspond to profitability $I_{R} \geq 0$ of the fleet operating, so the model should introduce an appropriate constraint:

$$
\begin{aligned}
& \frac{\sum_{j=1}^{n^{\prime}} \sum_{i \in G_{j}} \sum_{k=1}^{K_{j}} f_{i k_{j}} \cdot\left(Z_{i k_{j}}+Z_{i k_{j}}^{a d d}\right) \cdot s_{i k_{j}} \cdot p_{i k_{j}}}{\sum_{j=1}^{n^{\prime}} \sum_{i \in G_{j}} \sum_{k=1}^{K_{j}} r_{i k_{j}} \cdot\left(Z_{i k_{j}}+Z_{i k_{j}}^{a d d}\right) \cdot s_{i k_{j}} \cdot p_{i k_{j}}+} \\
& \overline{+r^{\text {add }} \sum_{j=1}^{n^{\prime}} \sum_{i \in G_{j}} \sum_{k_{j}=1}^{K_{j}} Z_{i k_{j}}^{\text {add }}} \geq I_{R} .
\end{aligned}
$$

In Equation $\sum_{j=1}^{n^{\prime}} \sum_{i \in G_{j}} \sum_{k=1}^{K_{j}} f_{i k_{j}} \cdot\left(Z_{i k_{j}}+Z_{i k_{j}}^{a d d}\right)$. $\cdot s_{i k_{j}} \cdot p_{i k_{j}}$ (31) describes the revenue component of the operation of the vessel in feeder services; and $\sum_{j n^{\prime}=1}^{n^{\prime}} \sum_{i \in G_{j}} \sum_{k_{\bar{K}}{ }^{1}}^{K_{j}} r_{i k_{j}} \cdot\left(Z_{i k_{j}}+Z_{i k_{j}}^{a d d}\right) \cdot s_{i k_{j}} \cdot p_{i k_{j}}+r^{\text {add }}$. $\cdot \sum_{j=1}^{n^{\prime}} \sum_{i \in G_{j}}^{i \in G_{j}} \sum_{k=1}^{k_{\overline{K_{j}}}} Z_{i k_{j}}^{\text {add }}$ are all the costs for the fleet operating and for the time-chartering of the additional tonnage.

Note that for many models on fleet distribution, it is typical to take into account just the final efficiency of the fleet, which is actual in solving the problem of container cargo servicing and subject to the secondary economic indicators. Therefore, for the actual situation on the container transport market, when every feeder service and operation of the vessel on it are commercially substantiated, it is necessary to introduce an additional constraint on the generalized efficiency of each service (here it means that the structure of the feeder service is determined at the next stage of the organization of feeder lines, therefore, at this stage, the feeder service is formed in general, in the form of a set of "hub ports - feeder ports").

$$
\frac{\sum_{j=1}^{n^{\prime}} \sum_{i \in G_{j}} \sum_{k=1}^{K_{j}} f_{i k_{j}} \cdot\left(Z_{i k_{j}}+Z_{i k_{j}}^{a d d}\right) \cdot s_{i k_{j}} \cdot p_{i k_{j}}}{\sum_{k=1}^{K_{j}} r_{i k_{j}} \cdot\left(Z_{i k_{j}}+Z_{i k_{j}}^{a d d}\right) \cdot s_{i k_{j}} \cdot p_{i k_{j}}-r^{a d d} \sum_{k_{j}=1}^{K_{j}} Z_{i k_{j}}^{a d d}} \geq I_{R}
$$

Note that these constraints can take into account "regional" profitability coefficients $I_{R} \geq 0,(j=\overline{1, n})$, which are related, for example, to the lower performance requirements for certain regions, for example, through a particular marketing strategy.

Thus, the model of perspective directions of operation of vessels "hub port - feeder ports" and the distribution of the company's fleet in these areas is established. Combining separate components of the model presented above, in the final version are obtained:

The objective function:

$$
\begin{aligned}
& \sum_{j=1}^{n^{\prime}} \sum_{i \in G j} \sum_{k_{j}=1}^{K_{j}}\left(f_{i k_{j}}-r_{i k_{j}}\right)\left(Z_{i k_{j}}+Z_{i k_{j}}^{a d d}\right) s_{i k_{j}} \cdot p_{i k_{j}}- \\
& -r^{a d d} \sum_{j=1}^{n^{\prime}} \sum_{i \in G j} \sum_{k_{j}=1}^{K_{j}} Z_{i k_{j}}^{a d d} \rightarrow \max .
\end{aligned}
$$

The constraint on the fleet general effectiveness:

$$
\begin{aligned}
& \frac{\sum_{j=1}^{n^{\prime}} \sum_{i \in G_{j}} \sum_{k=1}^{K_{j}} f_{i k_{j}} \cdot\left(Z_{i k_{j}}+Z_{i k_{j}}^{a d d}\right) \cdot s_{i k_{j}} \cdot p_{i k_{j}}}{\sum_{j=1}^{n^{\prime}} \sum_{i \in G_{j}} \sum_{k=1}^{K_{j}} r_{i k_{j}} \cdot\left(Z_{i k_{j}}+Z_{i k_{j}}^{a d d}\right) \cdot s_{i k_{j}} \cdot p_{i k_{j}}+} \\
& \overline{+r^{\text {add }} \sum_{j=1}^{n^{\prime}} \sum_{i \in G_{j}} \sum_{k_{j}=1}^{K_{j}} Z_{i k_{j}}^{\text {add }}} \geq I_{R} .
\end{aligned}
$$

The constraint on effectiveness of the feeder services for each hub port:

$$
\frac{\sum_{j=1}^{n^{\prime}} \sum_{i \in G_{j}} \sum_{k=1}^{K j} f_{i k_{j}} \cdot\left(Z_{i k_{j}}+Z_{i k_{j}}^{a d d}\right) \cdot s_{i k_{j}} \cdot p_{i k_{j}}}{\sum_{k=1}^{K_{j}} r_{i k_{j}} \cdot\left(Z_{i k_{j}}+Z_{i k_{j}}^{a d d}\right) \cdot s_{i k_{j}} \cdot p_{i k_{j}}-r^{a d d} \sum_{k j=1}^{K j} Z_{i k_{j}}^{a d d}} \geq I_{R} .
$$

The general compliance of the fleet distribution by volume of carriages:

$$
\begin{aligned}
& \sum_{j=1}^{n^{\prime}} \sum_{i \in G_{i}} \sum_{k_{j}=1}^{K_{j}}\left(X_{i k_{j}}^{i n}+X_{i k_{j}}^{o u t}\right)-\sum_{j=1}^{n^{\prime}} \sum_{i \in G_{i}} \sum_{k_{j}=1}^{K_{j}}\left(Z_{i k_{j}}+Z_{i k_{j}}^{\text {add }}\right) . \\
& \cdot S_{i k_{j}} \cdot p_{i k_{j}}=0
\end{aligned}
$$

The compliance of incoming container flows to the hub port with the volume of carriage in the direction from the given hub port to the feeder ports of the region:

$$
\begin{aligned}
& \lambda_{i j}^{i m p} \cdot Q_{i j}^{i m p}=\sum_{k_{j}=1}^{K_{j}} X_{i k_{j}}^{\text {out }}+\sum_{k_{j}=1}^{K_{j}} \sum_{l_{j}=2}^{L_{j}} v_{i k_{j}}^{\text {out }} . \\
& \cdot D_{i k_{j}}^{l_{j}} s_{i k_{j}}^{l_{j}} p_{i k j}^{l_{j}},\left(j=\overline{1, n}, i \in G_{j}\right) .
\end{aligned}
$$

The compliance of outgoing container flows from the port hub with the volume of carriage towards this hub port from the feeder ports of the region:

$$
\begin{aligned}
& \lambda_{i j}^{\exp } \cdot Q_{i j}^{\exp }=\sum_{k_{j}=1}^{K_{j}} X_{i k_{j}}^{i n}+\sum_{k_{j}=1}^{K_{j}} \sum_{l_{j}=2}^{L_{j}} v_{i k_{j}}^{i n} . \\
& \cdot D_{i k_{j}}^{l_{j}} s_{i k_{j}}^{l_{j}} p_{i k_{j}}^{l_{j}},\left(j=\overline{1, n}, i \in G_{j}\right) .
\end{aligned}
$$

The constraint on volumes of carriages, considering the attraction of cargo base to feeder ports:

$X_{i k_{j}}^{i n}+X_{i k_{j}}^{\text {out }} \leq Q_{i k_{j}}^{f p}\left(j=\overline{1, n}, i \in G_{j}, k_{j}=\overline{1, K_{j}}\right)$.

The constraint on the container capacity of the company's fleet:

$\sum_{j=1}^{n^{\prime}} \sum_{i \in G j} \sum_{k j=1}^{K_{j}} Z_{i k_{j}}=D^{*}$.

The constraint on the minimum acceptable container capacity of the feeder vessel:

$Z_{i k_{j}} \geq A,\left(j=\overline{1, n}, i \in G_{j}, k_{j}=\overline{1, K_{j}}\right)$.

The constraint on the acceptable size of the vessel according to characteristics of the feeder ports of the network:

$$
Z_{i k_{j}} \geq A_{i k_{j}},\left(j=\overline{1, n}, i \in G_{j}, k_{j}=\overline{1, K_{j}}\right) .
$$

The constraint of integrity of the control parameters:

$$
\begin{aligned}
& Z_{i k_{j}} \geq 0,\left(j=\overline{1, n}, i \in G_{j}, k_{j}=\overline{1, K_{j}}\right), \\
& Z_{i k_{j}}^{a d d} \geq 0,\left(j=\overline{1, n}, i \in G_{j}, k_{j}=\overline{1, K_{j}}\right),
\end{aligned}
$$




$$
\begin{aligned}
& X_{i k_{j}}^{i n} \leq 0,\left(j=\overline{1, n}, i \in G_{j}, k_{j}=\overline{1, K_{j}}\right), \\
& X_{i k_{j}}^{\text {out }} \leq 0,\left(j=\overline{1, n}, i \in G_{j}, k_{j}=\overline{1, K_{j}}\right) .
\end{aligned}
$$

Equations (33)-(46) is a nonlinear programming model due to the nonlinearity of the constraint on the profitability of the fleet as a whole and vessels in particular feeder directions.

The transformation of these constraints gives:

$$
\begin{aligned}
& \sum_{j=1}^{n^{\prime}} \sum_{i \in G_{j}} \sum_{k_{j}=1}^{K_{j}} f_{i k_{j}}\left(Z_{i k_{j}}+Z_{i k_{j}}^{a d d}\right) \cdot s_{i k_{j}} \cdot p_{i k_{j}} \geq \\
& \geq I_{R}\left(\sum_{j=1}^{n^{\prime}} \sum_{i \in G_{j}} \sum_{k j=1}^{K_{j}} r_{i k_{j}}\left(Z_{i k_{j}}+Z_{i k_{j}}^{a d d}\right) .\right. \\
& \left.\cdot s_{i k_{j}} \cdot p_{i k_{j}}-r^{a d d} \cdot \sum_{j=1}^{n^{\prime}} \sum_{i \in G_{j}} \sum_{k_{j}=1}^{K_{j}} Z_{i k_{j}}^{a d d}\right), \\
& \sum_{k_{j}=1}^{K_{j}} f_{i k_{j}}\left(Z_{i k_{j}}+Z_{i k_{j}}^{a d d}\right) \cdot s_{i k_{j}} \cdot p_{i k_{j}} \geq \\
& \geq I_{R_{j}}\left(\sum_{k_{j}=1}^{K_{j}} r_{i k_{j}}\left(Z_{i k_{j}}+Z_{i k_{j}}^{a d d}\right) \cdot s_{i k_{j}} \cdot p_{i k_{j}}\right),
\end{aligned}
$$

and allows one to bring the model to the class of linear programming.

\section{Conclusions}

The presented model allows the liner carrier to make the right decision not only to organize a container feeder line in a specific feeder region, but to evaluate the main container flows, to choose the most profitable region as possible, as well. The adopted restrictions on the level of profitability are set depending on the strategy and level of investment of the feeder operator. The model takes into account the level of competition in the region in the form of the total container capacity of the fleet, which already operates in the region. The bottleneck is the difficulty of obtaining complete and reliable information on volume and nature of the container flows (already operating and forecasting).

\section{References}

[1] RODRIGUE, J.-P., NOTTEBOOM, T. The geography of containerization: half a century of revolution, adaptation and diffusion. GeoJournal [online].2008, 74(1), p.1-5[accessed 2020-01-03]. ISSN 1572-9893. Available from: https://doi. org/10.1007/s10708-008-9210-4

[2] NOTTEBOOM, T., VERNIMMEN, B. The effect of high fuel costs on liner service configuration in container shipping. Journal of Transport Geography [online]. 2009,17(5), p.325-337[accessed 2020-02-03]. ISSN 0966-6923.Available from: https://doi.org/10.1016/j.jtrangeo.2008.05.003

[3] CHEN, G., YANG, Z. Optimizing time windows for managing export container arrivals at Chinese container terminals. Maritime Economics and Logistics. 2010, 12(1), p. 111-126.ISSN 1479-2931.

[4] CHANG, Y.-T., LEE, S-Y., TONGZON, J. Port selection factors by shipping lines: different perspectives between trunk liners and feeder service providers. Marine Policy[online]. 2008, 32(6), p. 877-885. ISSN 0308-597X. Available from: https://doi.org/10.1016/j.marpol.2008.01.003

[5] TAKANO, K., ARAI, M. A genetic algorithm for the hub-and-spoke problem applied to containerized cargo transport. Journal of Marine Science and Technology[online]. 2008, 14. p. 256-274 [accessed 2020-06-05]. eISSN 1437-8213. Available from: https://doi.org/10.1007/s00773-008-0035-0

[6] POLAT, O., GUNTHER, H.-O., KULAK, O. The containership feeder network design problem: the new Izmir port as hub in the black sea. In: 2nd International Conference on Logistics and Maritime Systems: proceedings.2012. p. 347-356.

[7] SHINTANI, K., IMAI, A., NISHIMURA, E., PAPADIMITRIOU, S. The container shipping network design problem with empty container repositioning. Transportation Research Part E: Logistics and Transportation Review. 2007, 43(1), p. 39-59. ISSN1366-5545.

[8] KOS, S., ZENZEROVIC, Z. Model of optimal cargo transport structure by full container ship on predefined sailing route. Promet-Traffic and Transportation [online]. 2004, 16(1), p. 15-20. ISSN0353-5320. Available from: https://traffic.fpz.hr/ index.php/PROMTT/article/view/568

[9] JI, M., SHEN, L., SHI, B., XUE, Y., WANG, F. Routing optimization for multi-type containerships in a hub-and-spoke network. Journal of Traffic and Transportation Engineering [online]. 2015, 2(5), p. 362-372. ISSN2095-7564. Available from: https://doi.org/10.1016/j.jtte.2015.08.008

[10] MARAS, V., KONINGS, R., RADMILOVIC, Z., DAVIDOVIC, T. Towards the optimal solution of feeder container ships routing with empty container repositioning. Jourmal of Maritime Research. 2012, 9(3), p. 11-20. ISSN 1697-4840. 